Document downloaded from:

http://hdl.handle.net/10251/45577

This paper must be cited as:

Cuenca Asensio, E.; Serna Ros, P. (2013). Shear behavior of prestressed precast beams made of self-compacting fiber reinforced concrete. Construction and Building Materials. 45:145-156. doi:10.1016/j.conbuildmat.2013.03.096>.

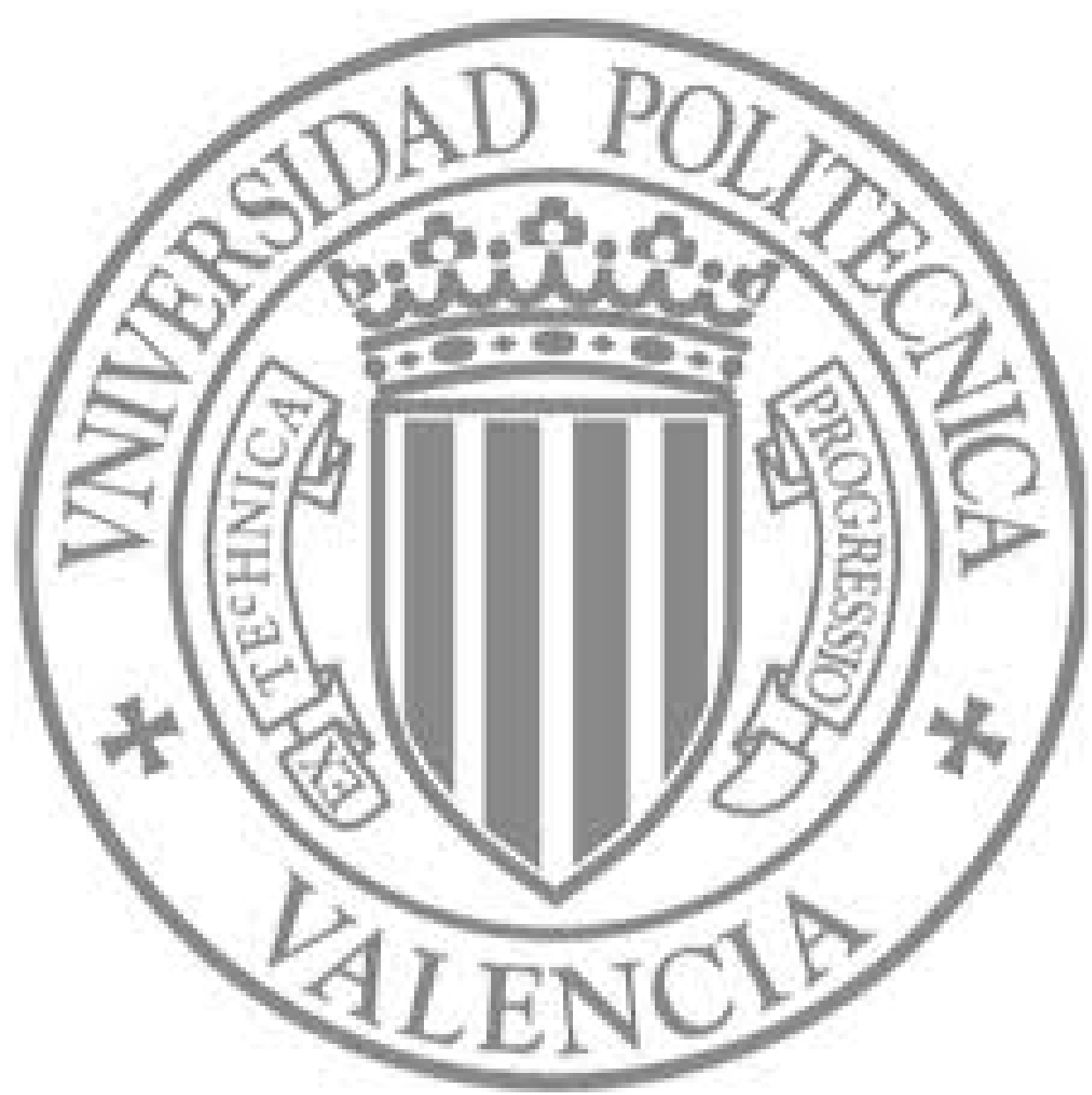

The final publication is available at

http://dx.10.1016/j.conbuildmat.2013.03.096

Copyright Elsevier 


\title{
Shear behavior of prestressed precast beams made of self-compacting fiber reinforced concrete
}

\author{
E. Cuenca ${ }^{a} ;$ P. Serna ${ }^{b}$ \\ Institute of Concrete Science and Technology (ICITECH), Universitat Politècnica de València, Camí de \\ Vera s/n, 46022 Valencia, Spain ${ }^{\text {a, b }}$ \\ escueas@upvnet.upv.es (corresponding author) ${ }^{a}$; pserna@cst.upv.es ${ }^{b}$
}

\begin{abstract}
This paper develops and explains the criteria for obtaining mix designs of self-compacting fiber reinforced concrete (SCFRC), the verification of their properties, the analysis of their production quality continuity in a precast industry and its ulterior application to produce prestressed concrete beams to minimize traditional transverse rebars.

An experimental program consisting in nine double-T prestressed beams was developed to analyze fiber contribution to shear behavior. Some of the main conclusions are: fibers act as additional reinforcement with stirrups; Codes are sufficiently safe as regards the shear ultimate limit state (ULS) but an in-depth study on the current Codes analyzing the influence of the parameters affecting shear strength is needed, EC2 does not take into account the positive effect of the fibers on the dowel action and this effect is too important to be neglected on beams with high longitudinal reinforcement ratios.
\end{abstract}

\section{Keywords}

Shear; A. Fibers; B. Strength; D. Mechanical testing; E. Casting

\section{Introduction}

Even after many years of in-depth research, the shear behavior of concrete structures is still to be updated and is a topic of continuous debate between researchers who are looking for models and methods to describe and determine the shear capacity of structural concrete members. General shear models are being extended to other materials such as fiber reinforced concrete (FRC). The FRC shear design workshop held in Salò (Italy) [1] proved to be an interesting advance in the development of the Model Code provisions [2,3] and in inspiring future research into these topics. Lectures were compiled in a fib Bulletin [1].

Many studies [4-28] have led to a number of experimental research works on FRC's shear resistance and to a good advance in our understanding of the shear behavior of FRC beams. The main ideas include: fibers are used to enhance the shear capacity of concrete, or to partially or totally replace stirrups in $\mathrm{RC}$ structural members [9, 29-31]; FRC is characterized by enhanced toughness due to the bridging effects provided by fibers [31, 32]; fibers provide substantial post-peak resistance and ductility [31, 33]; by adding fibers, less brittle shear failures take place e.g., [24-26, 30, 32, 34]; test results indicate that when fibers are applied, maximum crack width, average cracks width and average crack spacing decrease [17, 32, and 35]; FRC is suitable for structures where diffused stresses are present, and reinforcement is better in structures where both localized and diffused stresses are present because of a combination of rebars and fiber reinforcement [31].

RILEM TC162-TDF produced pioneer design guidelines [36] where fibers contribution to shear is added to concrete contribution as a separate term. 
The approach presented in the first complete draft of the Model Code $2010[2,3]$ to calculate FRC members' shear capacity is based on the Eurocode 2 equation [37], used to determine shear contribution in concrete members without shear reinforcement by adding a factor based on Minelli's proposal [38], which includes the FRC toughness properties by modifying the effect of the longitudinal reinforcement ratio. Then, fibers are included in concrete contribution. This was done to obtain a more representative modeling of the actual effect of fibers, which basically make the concrete matrix tougher after cracking by improving both the transfer of residual tensile stresses and the aggregate interlock (the latter, by keeping cracks smaller) [31]. However, we should note that the two formulations require toughness properties. When combining fibers and stirrups, both Codes include an additional term to consider the effect of stirrups.

In [31], the fittings of a wide experimental database between the proposed model [38] and the RILEM formulation [36] were compared. Although the fitting results are less promising when dealing with high strength concrete specimens or prestressed members, the RILEM results are slightly more refined for small-sized elements than for deep beams [31].

The ACI 318-08 Code [39] does not contain a formula to calculate the shear strength of SFRC beams, and only assumes a minimum shear strength which fibers can withstand. Parra-Montesinos [35] ensured that hooked steel fibers in a $0.75 \%$ volume fraction can be used in lieu of minimum stirrup reinforcement in beams. Evidently, a limit based on FRC's toughness properties (that does not only depend on the amount of fibers) would be a better criterion to justify substitution of transverse reinforcement.

Other countries have produced design guidelines [31], such as France (AFGC-SETRA, 2002), Sweden (Stälfiberbeton, 1995), Germany (DAfStb, 2007), Austria (Richtlinie Faserbeton, 2002), Italy (CNR, 2006) and Spain (EHE: Annex 14 [40]); the last one is based on RILEM.

Some of the main parameters usually considered to influence shear behavior are: element dimensions (size effect), presence or absence of axial forces, amount of longitudinal reinforcement, compressive concrete strength, load conditions, cross-section shape, the shear span/depth ratio (a/d) and the toughness properties of steel fibers. Some authors [41-45] have studied the effect of flange width on shear capacity with I and T-beams. Zsutty [44] proposed an equation to calculate the shear carried by concrete with a factor $h_{f}$ (flange thickness). However he considered it reasonable to ignore the strengthening effect of the flange for design purposes.

Current Design Codes do not include this effect in their formulation for plain concrete members. However, in the RILEM model, factor $\left(k_{f}\right)$ takes into account flanges contribution to shear due to fibers appearing.

These facts have encouraged authors to develop an experimental test program to analyze the influence of beam flange dimensions, as well as the combined effect of use of fibers with traditional transverse reinforcement (TR) on shear behavior.

The objective was to analyze shear behavior on real FRC prestressed beams, which are produced daily in a precast industry and are made with high-strength concretes. The main goals of this study were to:

- Propose a consistent SCFRC mix design adapted for continuous use in a precast industry.

- Evaluate the possibility of replacing all the transverse reinforcement and secondary rebars used for shear resistance in prestressed beams production.

- Analyze the current Codes that calculate shear strength capacity by means of their safety margins, which are obtained as the experimental to theoretical shear strength ratio.

- Check the possible influence of flange size on shear behavior.

\section{Concrete mix designs}


Reference SCC and a SCFRC with $60 \mathrm{~kg} / \mathrm{m}^{3}\left(\mathrm{~V}_{\mathrm{f}}=0.75 \%\right)$ of steel fibers were developed for this study. The aim of those concretes implied a nominal slump flow of $600 \mathrm{~mm}$ and an average compressive strength of about $60 \mathrm{MPa}$ at 28 days.

This objective was chosen to obtain self compacting concretes with good compressive strength at early ages which can be placed, without vibration; this is in line with precast prestressed beam production demands.

The materials used were a CEM I 52.5R cement type and calcareous crushed aggregates: filler, sand and $7 / 12 \mathrm{~mm}$ size coarse aggregates. The fibers used were low carbon steel hooked-end steel: 40mm length, $0.62 \mathrm{~mm}$ diameter, and a nominal aspect ratio (length/diameter) equal to 65 .

The water/cement ratio and the superplasticizer dosage were respectively determined to reach the required strength and slump flow.

SCC mix design criteria [46], most of which were based on laboratory tests, suggest an increase in fine content. Naturally, a final application needs experimental verification under working conditions. When SCC has fibers, the quantity of fines has to be increased.

Based on the authors' previous research work [47], the concrete mix design was determined by adapting solid grading (including cement) to the theoretical Bolomey particle size distribution curve [48], defined as:

$$
\mathrm{p}=\mathrm{a}+(100-\mathrm{a})(\mathrm{d} / \mathrm{D})^{1 / 2}
$$

where " $p$ " is the pass percentage through the " $d$ " sieve, " $\mathrm{D}$ " is the concrete's maximum aggregate size and "a" is the Bolomey parameter [48], which depends on the desired workability of the concrete and aggregates properties.

For the concretes in this paper, the " $a$ " values used were: $a=16$ for SCC and a=20 for SCFRC. A relatively low "a" parameter was used because well graded sand was available.

Table 1 shows the mix design for both concretes. In Figure 1, theoretical and actual particle size distribution curves are plotted.

\section{Concrete properties and production control}

In Figure 2, the flow of an SCFRC concrete into a beam formwork with no compacting process can be observed; a consistent mix design was obtained to be employed continuously in a precast industry.

To analyze the mix design robustness, an exhaustive production quality control took place in the experimental program. To cast all nine programmed beams, a $2 \mathrm{~m}^{3}$ mix was used. Concrete was casted according to the utilities and conditions of a precast industry. The following tests were done with a sample from each mix: the slump-flow test (EN 12350-8), a compressive strength test on $150 \times 300 \mathrm{~mm}$ cylinder specimens (EN 12390-3) and the flexural tensile strength test (EN 14651). The following was obtained from the flexural test: the limit of proportionality $\left(\mathrm{f}_{\mathrm{ctl}}\right)$ and the residual flexural tensile strength $\left(f_{R, j}\right)$ which corresponds to the crack mouth opening displacements (CMOD) linked to the crack openings (in $\mathrm{mm}$ ) of $0.5,1.5,2.5$ and 3.5 ( $\mathrm{j}=1,2,3,4$ respectively). All the mixes reached slump flow test values of between 550 and $710 \mathrm{~mm}$, which were sufficient to allow adequate concrete placing in the beams.

Table 2 shows the mechanical properties of the different concrete mixes. All the mechanical values were obtained as the average of three specimens 28 days after casting the beams. In order to analyze continuity on production, the averages, standard deviations (SD) and coefficients of variation (CoV) of the results are included. 
It is noteworthy that a brittle behavior of the fibers was observed during the flexural tensile strength tests, as deduced from the fact that $f_{R, 3}$ and $f_{R, 4}$ are clearly lower than $f_{R, 2}$. The 2 mm crack opening was often reached with the severance of several fibers without them sliding out of the concrete, and sometimes a brittle rupture was obtained before being able to determine the crack opening to $f_{R, 3}$ and $f_{R, 4}$. The values in Table 2 correspond to the results of at least two specimens.

The smallest variation was obtained for compressive strength with a $\mathrm{CoV}$ value of $8 \%$. Residual flexural strengths presented greater variability, with $\mathrm{CoV}$ values of between $13 \%$ and $22 \%$. This means than, even for residual flexural strength, dispersion can be controlled at levels only slightly higher than those obtained for compression strength in traditional concrete production when casting is performed under precast industry conditions.

Di Prisco [49] obtained a higher dispersion for the residual parameters, corresponding to an SCFRC used as a top slab (26.8\% to $34.6 \%$ ) when casting concrete with a small amount of fibers and under in situ production conditions.

\section{Experimental program and the results analysis}

\subsection{Main variables and beams production}

Nine six meters long double-T shaped prestressed beams were casted. Figure 3 shows the beams crosssection and reinforcement.

Beams were prestressed over-reinforced longitudinally with 11 tendons ( 0.6 " diameter with a nominal cross-section equal to $140 \mathrm{~mm}^{2}$ ) of 7 wires (Y $1860 \mathrm{~S} 7$ ). Their initial tension was $1354 \mathrm{MPa}$ (before prestress losses, which can approximately account for $26.2 \%$ ). This reinforcement guaranties a beam failure by shear when tested. This longitudinal reinforcement implies a $\rho_{l}=1.83 \%$ for all the beams, except for specimen HF400h/6 with $\rho_{l}=1.71 \%$. All the rebars used for stirrups or additional reinforcement were made out of steel B $500 \mathrm{~S}$ type.

The experimental program variables were:

- $\quad$ Top flange width (260 mm; $400 \mathrm{~mm} ; 600 \mathrm{~mm})$

- $\quad$ Concrete type (SCC or SCFRC)

- Presence or absence of traditional transverse reinforcement ( $\phi 8$ stirrups each $300 \mathrm{~mm}$ )

- Use of additional reinforcement, which is normally placed in beams made with SCC to control secondary failures (Figures 3 and 4)

- $\quad$ The effect of a depth increase of the top flange was also analyzed.

One type 7 of additional reinforcement was placed at both ends of all the beams to avoid longitudinal shear failures.

Table 3 shows the combination of variables for each tested beam.

\subsection{Testing procedure}

Beams were tested as simple supported and were subjected to two load points. The distance between supports was $5.00 \mathrm{~m}$ and the shear span/depth ratio (a/d) was 3.0 for all cases, except for beam HF400h/6 with $\mathrm{a} / \mathrm{d}=2.8$.

The two loads were applied to the beams by one $2500 \mathrm{kN}$ hydraulic jack. Loads were applied at a rate of $0.5-2.0 \mathrm{kN} / \mathrm{s}$. To monitor the behavior of the tested beams, the applied loads and vertical deflections were 
measured using a load cell and three displacement transducers placed on the middle span and over the middle of each shear span. All the variables were registered continuously by the data acquisition system. Photography and video equipment were also utilized in both the shear span zones on both sides of the beams. A synchronized recording system allowed us to report each photogram to the corresponding applied load. Later, the maximum shear crack opening versus the load curve was reported by means of a photo analysis. Figure 5 shows the test set up.

\subsection{Results}

As expected, all the beams had a shear failure and presented diagonal cracks with flexural cracks of very little consequence. Table 4 offers the maximum load obtained for each beam. Greater shear capacity was obtained when stirrups and fiber acted simultaneously (Beams 1 and 2), reaching a value of $18.5 \%$ higher than that of the beam with only traditional stirrups (Beam 3). No significant difference was found between the two beams with both stirrups and fibers. The additional reinforcement types 3 and 4 in Beam 2 did not imply any shear capacity improvement.

The beam with only stirrups also presented greater shear strength (an average of 30.4\%) than all the other beams with only fibers as shear reinforcement.

The differences among the beams with only fibers as shear reinforcement were clearly less significant. No influence of flange width on the shear strength experimental value was detected (Figure 6). Table 4 provides the test values of the shear strength of only fiber reinforced beams of the same height. The low $\mathrm{CoV}$ value $(9.62 \%)$ was similar to the compressive strength dispersion found in this research and indicates lack of flange influence.

In contrast, a slight influence of additional reinforcement (types 2, 3, and 4) was detected when a greater shear strength was obtained in Beams 4 and 8 . At any rate, this trend was neither significant nor consistent with that observed when comparing Beams 1 and 2.

If fibers contribution to shear depended on fibers efficiency, it would be possible to find a correlation between the shear strength of the beams and their concrete flexural residual strength. Nevertheless, no clear trend was obtained (Figure 7), meaning that the flexural test method dispersions were greater than the effect on beam shear capacity.

Based on this reflection, when analyzing the parameters influencing shear capacity (see 4.4), concrete residual flexural strength was considered a fix parameter, which was evaluated as the average of the residual strength obtained in the eight beams made with fibers. Identical criteria were applied for concrete compressive strength.

\subsubsection{Load Deflection Response}

Figure 8 shows the Load-mid span deflection response for one beam for each combination of top flange width and shear reinforcement conditions. In order to obtain a clearer graph, other beams were eliminated to provide no additional information. Compared with other tested beams, those with stirrups and fiber shear reinforcement showed a ductile failure with controlled post-peak behavior. All the other beams, including this one with only stirrups and no fibers, revealed brittle failure with a sharp drop after the peak. No clear differences in ductility (post-peak behavior) were observed between the beams reinforced only with either fibers or TR.

\subsubsection{Cracking pattern and the Load-Crack width response}

The cracking pattern evolution on shear span at different loads is illustrated in Figure 9 as a selection of the main types of beams with the same geometry. Figure 10 represents the Load-Crack width response of these same beams. These figures allow us to analyze the influence of their shear reinforcement: transverse reinforcement (TR), fibers, or both. The other analyzed variables produced no remarkable difference in 
this behavior. These figures enable an assessment of the width, quantity and spacing among the cracks throughout the loading process.

The average crack inclination was very close to $22^{\circ}$ for all the beams.

For those beams reinforced to shear only with fibers (Beam 4), only a few cracks developed upon low loads, and but one of them opened quickly. For Beam 3, which had only traditional reinforcement, cracks were more profuse, very straight and extremely parallel. Upon very low loads, some crack openings close to $0.3 \mathrm{~mm}$ were noted and rapidly progressed; consequently, this beam must not be considered to be in service conditions. For all the SCFRC beams, and for the beam with only TR, the crack which produced the failure either coincided with a previous crack or was generated from previous cracks. For Beam 2 (which had traditional reinforcement and fibers), a larger number of cracks developed, with a narrower gap between them and a thin opening remained. It was necessary to reach a high load level to appreciate shear cracks, and shear cracks reached values of $0.2 \mathrm{~mm}$ only near ultimate loads. Cracks increased gradually, but in a way that was easy to control. The crack that finally produced the failure developed upon a very high load, involved two previous parallel cracks and produced a flatter final crack slope.

In conclusion, clearly improved ductility was detected only when TR was placed on an SCFRC beam and when addition of fibers to the traditional transverse reinforcement led to a $35 \%$ increment in the maximum load for the same crack width. The crack width of the beam with traditional transverse reinforcement only (Beam 3) was $0.4 \mathrm{~mm}$ for a load of $750 \mathrm{kN}$. The same beam, but with fibers (Beam 2), reached an ultimate, $35 \%$ higher load $(1150 \mathrm{kN})$ than without fibers.

\subsection{Shear values calculated with the current Design Codes}

Shear strength capacities were calculated by the formulation of current Codes EHE08 [40], EC2 [37] and MC2010 [2, 3]. As EC2 has no formulation which takes into account fiber contribution, it was calculated by following the RILEM approach [36].

Notation (Appendix A) and formulas presentation have been adapted to facilitate their comparison. In this way, formulas take the following general structure:

$$
\mathrm{V}_{\mathrm{u} 2}=\left(\mathrm{V}_{\mathrm{cu}}+\mathrm{V}_{\mathrm{fu}}\right)+\mathrm{V}_{\mathrm{su}}
$$

All the Codes consider the traditional transverse reinforcement contribution $\left(\mathrm{V}_{\mathrm{su}}\right)$ in the same way and are evaluated according to the following expression:

$$
\mathrm{V}_{\mathrm{su}}=\mathrm{z} \cdot \operatorname{sen} \alpha \cdot(\operatorname{cotg} \alpha+\operatorname{cotg} \theta) \Sigma \mathrm{A}_{\alpha} \cdot \mathrm{f}_{\mathrm{y} \alpha, \mathrm{k}}
$$

Table 6 shows the expression for the concrete $\left(V_{c u}\right)$ and fibers $\left(V_{f u}\right)$ contributions of each Code.

No Code considers any explicit influence of cracks inclination on the fibers contribution evaluation or proposes any fibers effect on the $\theta$ value to be considered in the shear reinforcement contribution $\left(\mathrm{V}_{\mathrm{su}}\right)$. Consequently, fibers are considered separately to TR. On the other hand, the inclination of compression stresses $\theta$ was assumed equal to that obtained with the corresponding expression of Model Code -Level III of Approximation- (see Expression B.13 from Appendix B) for all the Codes.

In this way, the theoretical shear strength values were calculated by the following criteria for each Code:

-MC2010: Beam 3 (without fibers) was calculated by applying the most accurate form (Level III of Approximation), which permits the calculation of $\varepsilon_{\mathrm{x}}$ and directly calculates the corresponding inclination of the compression stresses $(\theta)$. Level III of Approximation was based directly on the equations of the Modified Compression Field Theory (MCFT) [50]. Other beams (with fibers) were calculated by applying the formula proposed in MC 2010 (see Chapter 7.7), which includes the effect of fibers inside the concrete matrix contribution. 
-EHE08: This reference angle of cracks inclination $\left(\theta_{\mathrm{e}}\right)$ was taken to equal the inclination of compression stresses $(\theta): \theta=\theta_{\mathrm{e}}$.

-EC2: When considering TR shear contribution, EC2 neglects the concrete contribution to shear $\left(\mathrm{V}_{\mathrm{cu}}\right)$. Several authors, including the EC2 authors, have doubts about concrete contribution to shear when TR is needed. Cladera and Marí $[51,52]$ concluded that the EC2 procedure is very easy to use but its results are very scattered. On the one hand, it may be too conservative for slightly shear-reinforced beams or for prestressed beams; on the other hand, it may prove slightly underestimated for heavily reinforced members.

To obtain real predictable resistance concrete, partial safety factors for material properties were considered in the calculation as $\gamma_{c}=1$ and $\gamma_{s}=1$. Moreover, average values were utilized when a characteristic value appeared in a formula.

Code formulas include limitations on several parameters such as the $\rho_{l}$ reinforcement ratio for longitudinal reinforcement, the $\xi$ factor which takes into account the size effect, the $\sigma_{c k}$ average stress acting on the concrete cross-section for an axial force due to prestressing actions and minimum concrete contribution to shear $\mathrm{V}_{\mathrm{cu}}$, as presented in Appendix B. None of these limitations affected the values calculated in the beams tested for this paper.

Table 6 presents the theoretical shear strength values calculated with the current Codes for each beam. Figures 11-a and 11-b represent contributions to shear by means of concrete, stirrups and fibers for the current Codes: the Spanish Code EHE08, EC2 and MC2010 for all of the beams tested. In Figure 11-a, the results were evaluated by considering average values without applying safety factors. Figure 11-b reproduces the values evaluated by considering design values. Design values were obtained by dividing the characteristic value by its corresponding material safety factor.

As all the formulas (except MC2010 for concrete without fibers) include an identical and explicit term after considering the favorable effect of prestressing reinforcement on concrete contribution, a line with the level of this effect has been represented in Figures 11-a and 11-b.

Figure 11-b shows how the fibers effect is underestimated by the Codes, mostly by MC2010. Finally, Table 7 reports the shear contributions as a percentage due to stirrups, concrete and fibers.

\subsubsection{Flange effect on shear strength.}

The $k_{f}$ factor in Codes EHE08 and RILEM, which takes into account flange contribution in the T-sections calculated by the formula in Appendix B, was equal to 1 for rectangular sections, yet increased when there was a flange. With the cases presented herein, $k_{f}$ was equal to 1.5 for width flanges of up to $400 \mathrm{~mm}$, which did not differentiate any flange effect among the beams studied in this paper with a flange width of up to $400 \mathrm{~mm}$. In contrast, $k_{f}$ equaled 1.35 for the smallest flange width tested $(260 \mathrm{~mm})$.

In Figure 12, the EC2 safety margins were plotted for the beams only reinforced with steel fibers. In this graph, the theoretical values were obtained with the EC2 formulations, and the RILEM proposal was added to evaluate the shear contribution due to steel fibers. Four different options were calculated:

1. $k_{f}=1.5$ was applied to all the cases.

2. Without the $k_{f}$ application, then $k_{f}=1$.

3. $k_{f}$ was applied exactly as proposed in the RILEM approach.

4. $k_{f}$ was applied as proposed in the RILEM approach, but without its limitations (see B.5 and B.6 in Appendix B).

When $k_{f}$ was not applied (2 $2^{\text {nd }}$ option), highly conservative SM (safety margin) values were obtained.

If we observe the $4^{\text {th }}$ option ( $k_{f}$ without limitation), it is clear that SM lowered for $600 \mathrm{~mm}$ flange widths, meaning that the application of limitations was necessary. 
The most balanced option (when comparing the theoretical and experimental results) may be obtained by applying the corresponding $k_{f}$ value ( $3^{\text {rd }}$ option) for the cases in which $h_{f}>400 \mathrm{~mm}$. Only the beam with a low $k_{f}$ value $\left(h_{f}=260 \mathrm{~mm}\right)$ was not conservative enough with this criterion. For this width flange, $k_{f}=1$ had to be applied.

\subsubsection{Assessment of shear formulations from current Design Codes.}

The safety margins (SM) obtained as $\mathrm{V}_{\text {test }} / \mathrm{V}_{\text {theo }}$ (the shear test value divided by the shear theoretical value) were used as a reference parameter to compare the results obtained from the different beams and Codes.

In order to achieve a more complete analysis of the SM of the current Design Codes, Figure 13 shows how the SM of the different analyzed Codes were plotted for the beams tested in the experimental program presented herein, along with six more beams corresponding to Minelli's $\mathrm{PhD}$ thesis [38]. Minelli's beams were similar to our HF600 series (prestressed, reinforced only with fibers, 700mm depth and $600 \mathrm{~mm}$ flange width).

The toughness properties of Minelli's concretes were obtained by means of four point bending tests to determine equivalent strengths such as $f_{\text {eq(0.6-3.0) }}$ usually, these values have been assumed to be $f_{R 3}$ in the literature. For calculation purposes, it was assumed that $f_{R 3}=f_{R 4}$ to be able to apply the same criteria to the Minelli database beams.

We observed that applying the longitudinal reinforcement ratios limit, which equaled $2 \%$, when the actual reinforcement was much higher (which is the case of Minelli's database) conferred shear strength estimations which were too conservative. This reasoning, coupled with the assertion of Cladera [53] which ensures that the limitation of longitudinal reinforcement could be extended from $2 \%$ to $4 \%$, led the authors to apply the real longitudinal reinforcement ratio.

The graph represented in Figure 13 is divided into three parts: beams reinforced only with stirrups, stirrups with fibers and, finally, only reinforced fiber. Moreover, beams were arranged in descending order according to their flange width.

All the Codes presented safety margins greater than "1", which means a safe shear strength evaluation.

If we observe the beams only reinforced with fibers, MC2010 was the most balanced one for all the flange widths. This formula considered the whole effect of fibers as it multiplied the longitudinal reinforcement ratio by a parameter which included the compressive strength and toughness properties of the FRC. In this way, the fibers effect, that of improving the dowel action by increasing the bond between the rebar and concrete matrix, as proposed by Swamy [5], was implicit. The dowel action improvement due to fibers was too important for beams with very high longitudinal reinforcement ratios $\left(\rho_{l}>2 \%\right)$ to not be considered, as with EC2. Therefore, the application of EC2, with RILEM or EHE08's formulas, to Minelli's beams with large amounts of longitudinal reinforcement $\left(\rho_{l}\right)$ led to higher SM.

The current MC2010 formula for FRC offers a major advantage if compared with EC2 because MC2010 multiplies the longitudinal reinforcement ratio by the compressive strength and the toughness properties of the FRC. On the other hand, EC2 does not consider the toughness properties on the longitudinal reinforcement ratio. It is known that fibers improve the dowel action because they improve the bond between the rebar and the concrete matrix, as in Swamy [5], who ensured that fibers enable beams to fully use the shear contribution due to the dowel action; moreover, this fact must be included in the Design Codes as has been done with the MC2010 formulation for FRC elements.

MC2010 is highly conservative for all cases with FRC beams. It is important to remember that the limit of the longitudinal reinforcement ratios was equal to $2 \%$ and has not been applied in the values evaluation in Figure 13. Otherwise the SM obtained for the Minelli's beams should be higher. 
EC2 was excessively conservative when stirrups were placed because concrete contribution to shear was neglected.

When stirrups were present, MC2010 with Level III of Approximation, or EHE08, were clearly better adjusted. In these cases, SM were close to 1.2, and were visibly narrower than those obtained for FRC (about 1.5). This may be justified by less confidence in the continuity of the FRC toughness properties. Obviously, additional studies must be done to reach and validate a more adjusted proposal.

\section{Conclusions}

An SCFRC has been casted with good production continuity according to the slump flow test and its compressive strength and flexural behavior under industrial conditions, and with low levels of quality variability.

An experimental program including shear tests on nine prestressed FRC double T-beams has been developed. The results indicate that inclusion of steel fibers provides a more ductile behavior after the maximum load. According to the analysis of failure modes, deflections and cracking patterns, the following conclusions can be drawn:

- Steel fibers control not only the appearance of cracks, but also their propagation.

- With steel fibers, more cracks are created, but these are narrower than without fibers, and the gap between them is also smaller.

- Steel fibers positively interact with traditional transverse reinforcement (additive effect), conferring an important contribution to the tension stiffening mechanism.

- EC2 is highly conservative when stirrups are present, because concrete contribution to shear is neglected.

- According to the flange width influence, the results obtained for tested beams indicate that the presence of a flange does not clearly produce a difference in the ultimate load capacity. These results are in agreement with the fact that the $k_{f}$ factor, which takes into account the contribution of flanges on shear according to RILEM, does not vary for $h_{f}>400 \mathrm{~mm}$.

- The RILEM approach does not consider the positive effect of fibers on the dowel action. Its application leads to results which vary vastly with the longitudinal reinforcement ratio.

- MC2010 bears in mind the positive effect of fibers on the dowel action. In this way, fibers contribution increases when beams have high longitudinal reinforcement ratios. MC2010 shows well balanced SM for a variable range of flange widths $\left(h_{f}\right)$ and reinforcement ratios. However, these SM have highly very conservative values.

- Even though all the Codes underestimate the fiber effect on shear, a less conservative approach is needed in the MC2010 proposal.

\section{Acknowledgements}

The authors of this work wish to thank the research bureau of the Spanish Ministry of Science and Innovation and the Plan E, for the funding of the project "BIA 2009-12722" . The collaboration of the precast industry "PREVALESA S.L" is also acknowledged.

\section{References}

[1] fib Bulletin 57. Shear and punching shear in RC and FRC elements. Workshop proceedings 2010. 268 pp., ISBN 978-2-88394-097-0.

[2] fib Bulletin 55. Model Code 2010 - First complete draft, 2010; Vol.1, 318 pp., ISBN 978-2-88394095-6. 
[3] fib Bulletin 56. Model Code 2010 - First complete draft, 2010; Vol.2, 312 pp., ISBN 978-2-88394096-3.

[4] Batson G, Jenkins E, Spatney R. Steel fibers as shear reinforcement in beams. ACI Journal1972; 69(10):640-644.

[5] Swamy R N, Bahia H M. The effectiveness of steel fibers as shear reinforcement. Concrete International 1985;7(3):35-40.

[6] Swamy R N, Jones R, Chiam A. Influence of steel fibers on the shear resistance of lightweight concrete T-beams. ACI Structural Journal 1993; 90(1):103-114.

[7] Ashour, S A, Hasanain G S, Wafa F F. Shear behavior of high-strength fiber reinforced concrete beams. ACI Structural Journal 1992; 89(2):176-184.

[8] Tan K H, Murugappan K, Paramasivam P. Shear behavior of steel fiber reinforced concrete beams. ACI Structural Journal 1993; 90(1):3-11.

[9] Imam M, Vandewalle L, Mortelmans F, Van Gemert D. Shear Domain of Fibre-Reinforced HighStrength Concrete Beams. Engineering Structures 1997; 19 (9):738-747.

[10] Adebar P, Mindess S, St-Pierre D, Olund B. Shear tests of fiber concrete beams without stirrups. ACI Structural Journal1997; 94(1):68-76.

[11] Casanova P, Rossi P, Schaller I. Can steel fibers replace transverse reinforcement in reinforced concrete beams?. ACI Material Journal 1997; 94(5):341-354.

[12] Khuntia M, Stojadinovic B, Goel S. Shear Strength of normal and high-strength fiber reinforced concrete beams without stirrups. ACI Structural Journal1999; 96(2):282-289.

[13] Lim D H, Oh B H. Experimental and theoretical investigation on the shear of steel fiber reinforced concrete beams. Engineering Structures1999; 21(10):937-944.

[14] Gustafsson J, Noghabai K. Steel fibers as shear reinforcement in high strength concrete beams. Technical Report, Lulea University of Technology, Division of Struvtural Engineering 1999; 1-18.

[15] Rosenbusch J, Teutsch M. Trial beams in shear. Brite/Euram Project 97-4163, Final Report, Sub Task 4.2, Technical University of Braunschweig, 2002.

[16] Kwak Y-K, Eberhard M-O, Kim W-S, Kim J. Shear strength of steel fiber-reinforced concrete beams without stirrups. ACI Structural Journal 2002; 99(4):530-538.

[17] Kovács I, Balázs G L. Structural behavior of steel fiber reinforced concrete. Journal of Structural Concrete 2003:57-63.

[18] Meda A, Minelli F, Plizzari G A, Riva P. Shear behaviour of steel fibre reinforced concrete beams. Materials and Structures 2005; 38:343-351.

[19] Minelli F, Plizzari G A. Steel fibers as shear reinforcement for beams. Proceedings of the second Fib Congress, Naples, Italy, 5-8 June 2006.

[20] Minelli F, Vecchio F. Compression Field Modelling of Fiber-Reinforced Concrete Members under shear loading. ACI Structural Journal 2006; 103(2):244-252.

[21]Cuenca E, Serna P. Failure modes and shear design of prestressed hollow core slabs made of fiberreinforced concrete. Composites Part B: Engineering. Accepted and published online. http://dx.doi.org/10.1016/j.compositesb.2012.06.005. ISSN 1359-8368 
[22] Parra-Montesinos G. Shear strength of beams with deformed steel fibers. Concrete International 2006; 28(11):57-66.

[23] Choi K-K, Park H-G, Wight J. Shear Strength of steel fiber-reinforced concrete beams without web reinforcement. ACI Structural Journal 2007; 104(1):12-22.

[24] Cuenca E, Serna P, Pelufo M.J. Structural behavior of self-compacting and fiber reinforced concrete under shear loading. Proceedings of the International Association for Shell and Spatial Structures (IASS) Symposium 28 September -2 October 2009, Valencia Spain.

[25] Cuenca E, Serna P. Shear behavior and Mode of Failures analysis of different structural elements made with fiber reinforced concrete. $8^{\text {th }}$ fib PhD Symposium in Kgs. Lyngby, Denmark June 20-23 2010.

[26] Cuenca E, Serna P. Shear behavior of self-compacting concrete and fiber reinforced concrete beams. $6^{\text {th }}$ International RILEM Symposium on Self-Compacting Concrete SCC2010, Montreal, Canada 2010.

[27] Dinh H, Parra-Montesinos G, Wight J. Shear behavior of steel fiber-reinforced concrete beams without stirrup reinforcement. ACI Structural Journal 2010; 107(5):597-606.

[28] Conforti A, Cuenca E, Minelli F, Plizzari G A. Can we mitigate or eliminate size effect in shear by utilizing steel fibers. Proceedings of the Fib Symposium on Concrete Engineering for Excellence and Efficiency, Prague, Czech Republic, 8-10 June 2011, Vol 1 pp. 159-162, ISBN 978-80-87158-29-6.

[29] Foster S. Design of FRC beams for shear using the VEM and the draft Model Code approach. fib Bulletin 2010; 57(12):195-210.

[30] Minelli F, Plizzari G A. Shear strength of FRC members with little or no shear reinforcement: a new analytical model. fib Bulletin 2010; 57(13):211-225.

[31] Di Prisco M, Plizzari G, Vandewalle L. MC2010: Overview on the shear provisions for FRC. fib Bulletin 2010; 57(4):61-76.

[32] Susetyo J, Vecchio F J. Effectiveness of steel fiber as minimum shear reinforcement: panel tests. fib Bulletin 2010; 57(14):227-241.

[33] Balázs G L. A historical review of shear. fib Bulletin 2010; 57(1):1-13.

[34] Cucchiara C, La Mendola L, Papia M. Effectiveness of stirrups and steel fibers as shear reinforcement. Cement and Concrete Composites 2004; 26(7):777-786.

[35] Parra-Montesinos G J, Wight J K, Dinh H H, Cheng M-Y. Use of steel fiber reinforcement for shear resistance in beams and slab-column connections. fib Bulletin 2010; 57(15):243-262.

[36] RILEM. RILEM TC 162-TDF: Test and design methods for steel fibre reinforced concrete, $\sigma$ - $\varepsilon$ Design method. Final Recommendation. RILEM 2003; 36:560-567.

[37] European Committee for Standardization. Eurocode 2: Design of Concrete Structures - EN 1992-1$1,2005$.

[38] Minelli F. Plain and Fiber Reinforced Concrete Beams under Shear Loading: Structural Behavior and Design Aspects. PhD Thesis, Department of Civil Engineering, University of Brescia 2005, 430 pp. ISBN 88-89720-30-1.

[39] ACI Committee 318. Building Code Requirements for Structural Concrete - ACI 318-08- and Commentary. American Concrete Institute, Farmington Hills, MI, 2008, 473 pp. 
[40] Comisión Permanente del Hormigón. Instrucción de Hormigón Estructural EHE-08. Ministerio de Fomento, 2008, 702 pp.

[41] Leonhardt F. Shear and torsion in Prestressed Concrete. FIP Congress, Prague 1970.

[42] Leonhardt F, Walther R. The Stuttgart Shear Tests, 1961. Cement and Concrete Association 1964.

[43] Placas A, Regan P E. Shear Failures of Reinforced Concrete Beams. Proceedings, American Concrete Institute 1971; 68:763-773.

[44] Zsutty T. Unpublished memorandum to Reinforced Concrete Research Council 1972.

[45] ACI-ASCE Committee 426. The Shear Strength of Reinforced Concrete Members. Journal of Structural Division ASCE 1973; 99(6):1091-1187.

[46] EFNARC. The European Guidelines for Self-Compacting Concrete. Specification, Production and Use, 2005. URL: http://www.efnarc.org/pdf/SCCGuidelinesMay2005.pdf

[47] Serna P, Cuenca E, Alves de Oliveira M. Self-compacting fiber reinforced in precast elements production for shear resistance. Dedicated to Innovation: 50 years MC-Bauchemie. MC-Bauchemie Müller GmbH Co. KG. 2011.

[48] Bolomey J. The Grading of Aggregate and its influence on the characteristics of concrete. Revue des Matériaux de Construction et des Travaux Publiques, 1947.

[49] Di Prisco M, Plizzari G, Vandewalle L. Fibre reinforced concrete: new design perspectives. Materials and Structures 2009; 42:1261-1281.

[50] Vecchio F, Collins M. The Modified compression Field Theory for reinforced concrete elements subjected to shear. ACI Journal 1986; 83(2):219-231.

[51] Cladera A, Marí A R. Shear strength in the new Eurocode 2. A step forward?. Structural Concrete 2007; 8 (2):57-66.

[52] Cladera A, Marí A R. Shear design procedure for reinforced normal and high-strength concrete beams using artificial neural networks. Part II: beams with stirrups. Engineering Structures 2004; $26: 927$ 936.

[53] Cladera A, Marí A R. Shear design procedure for reinforced normal and high-strength concrete beams using artificial neural networks. Part I: beams without stirrups. Engineering Structures 2004; 26(7):917-926.

\section{FIGURE CAPTIONS}

Fig. 1. Theoretical versus actual particle size distribution curves for selecting the mix design

Fig. 2. Concrete pouring into the formwork

Fig. 3. Cross-section. Dimensions in mm.

Fig. 4. Additional reinforcement typologies. Dimensions in $\mathrm{mm}$.

Fig. 5. Beam during shear test

Fig. 6. Vtest $(\mathrm{kN})$ comparison of fiber-reinforced beams with a variable top flange width. 
Fig. 7. Vtest $-\mathrm{fRj}$ response for each beam (the number of the beam is next to each point).

Fig. 8. Load-deflection responses on middle span.

Fig. 9. Cracking patterns. Crack appearance and its corresponding load level.

Fig. 10. Crack widths (mm) on beams for different shear reinforcement combinations.

Fig. 11-a. Contributions of concrete, stirrups and fibers to the ultimate theoretical shear strength capacity (average values).

Fig. 11-b. Contributions of concrete, stirrups and fibers to the ultimate theoretical shear strength capacity (design values).

Fig. 12. SM variations when different flange factor values are applied.

Fig. 13. Safety Margin $=$ Vtest $/$ Vtheo without safety factors 
Table 1

Mix design adaptation $\left(\mathrm{kg} / \mathrm{m}^{3}\right)$.

\begin{tabular}{l|cc}
\hline \multicolumn{1}{c}{$\left(\boldsymbol{k g} / \boldsymbol{m}^{\mathbf{3}}\right)$} & $\boldsymbol{S C C}$ & $\boldsymbol{S C F R C}$ \\
\hline 7/12 aggregate & 846 & 721 \\
Sand & 924 & 985 \\
Filler & 41 & 50 \\
Cement & 440 & 460 \\
Water & 198 & 205 \\
Fibers & 0 & 60 \\
Superplasticizer & 11.1 & 12.8 \\
W/C ratio & 0.45 & 0.45 \\
\hline
\end{tabular}


Table 2

Mechanical concrete properties.

\begin{tabular}{c|cccccc}
\hline Specimen $\boldsymbol{I D}$ & $\boldsymbol{f}_{\boldsymbol{c}}[\mathbf{M P a}]$ & $\boldsymbol{f}_{\boldsymbol{c t l}}[\mathbf{M P a}]$ & $\boldsymbol{f}_{\boldsymbol{R} 1}[\mathbf{M P a}]$ & $\boldsymbol{f}_{\boldsymbol{R} 2}[\mathbf{M P a}]$ & $\boldsymbol{f}_{\boldsymbol{R} 3}[\mathbf{M P a}]$ & $\boldsymbol{f}_{\boldsymbol{R} 4}[\mathbf{M P a}]$ \\
\hline HF600TR/1 & 61.1 & 3.36 & 5.26 & 5.13 & -- & -- \\
HF600TR/2 & 65.7 & 4.39 & 9.36 & 9.56 & 6.89 & 4.96 \\
H600TR/3 & 52.4 & 3.64 & -- & -- & -- & -- \\
HF600/4 & 65.4 & 4.70 & 10.46 & 7.99 & 6.24 & 5.12 \\
HF600/5 & 65.9 & 4.20 & 8.55 & 8.43 & 5.55 & 3.92 \\
HF400h/6 & 59.5 & 4.45 & 8.96 & 7.49 & 5.96 & 4.57 \\
HF400/7 & 63.5 & 4.08 & 6.64 & 6.70 & 4.77 & 3.41 \\
HF400/8 & 70.0 & 4.33 & 8.10 & 7.02 & 4.68 & 3.13 \\
HF260/9 & 65.0 & 3.11 & 6.45 & 4.38 & -- & -- \\
\hline Average & 63.17 & 4.03 & 7.97 & 7.09 & 5.68 & 4.18 \\
SD & 4.75 & 0.51 & 1.61 & 1.59 & 0.79 & 0.75 \\
CoV $(\%)$ & 8 & 13 & 20 & 22 & 14 & 18 \\
\hline
\end{tabular}


Table 3

Main study variables

\begin{tabular}{c|ccccc}
\hline $\begin{array}{c}\text { Specimen } \\
\text { ID }\end{array}$ & $\begin{array}{c}\text { Top flange } \\
\text { width }(\mathbf{m m})\end{array}$ & $\begin{array}{c}\text { Transversal } \\
\text { reinforcement }\end{array}$ & $\begin{array}{c}\text { Fibers } \\
\left(\mathbf{k g} / \mathbf{m}^{\mathbf{3}}\right)\end{array}$ & $\begin{array}{c}\text { Plus depth } \\
(\mathbf{m m})\end{array}$ & $\begin{array}{c}\text { Additional } \\
\text { reinforcements } \\
\text { (types })\end{array}$ \\
\hline HF600TR/1 & 600 & $\mathrm{c} \phi 8 / 300$ & 60 & 0 & $2,3,4$ \\
HF600TR/2 & 600 & $\mathrm{c} \phi 8 / 300$ & 60 & 0 & 2 \\
$\mathrm{H} 600 \mathrm{TR} / 3$ & 600 & $\mathrm{c} \phi 8 / 300$ & 0 & 0 & $2,3,4$ \\
\hline HF600/4 & 600 & 0 & 60 & 0 & $2,3,4$ \\
HF600/5 & 600 & 0 & 60 & 0 & - \\
HF400h/6 & 400 & 0 & 60 & 50 & - \\
HF400/7 & 400 & 0 & 60 & 0 & - \\
HF400/8 & 400 & 0 & 60 & 0 & $2,3,4$ \\
HF260/9 & 260 & 0 & 60 & 0 & - \\
\hline
\end{tabular}


Table 4

Experimental shear strength $(\mathrm{kN})$ for each tested beam.

\begin{tabular}{c|c|c}
\hline Specimen ID & $\boldsymbol{V}_{\text {test }}$ & $\begin{array}{c}\boldsymbol{V}_{\text {test }} \\
\text { (Beams only } \\
\text { with fibers, } \\
\text { not TR) }\end{array}$ \\
\hline HF600TR/1 & 571.61 & \\
HF600TR/2 & 592.70 & \\
H600TR/3 & 491.34 & \\
\hline HF600/4 & 392.44 & 392.44 \\
HF600/5 & 347.17 & 347.17 \\
HF400h/6 & 420.03 & \\
HF400/7 & 389.95 & 389.95 \\
HF400/8 & 428.31 & 428.31 \\
HF260/9 & 325.58 & 325.58 \\
\hline Average & & 376.69 \\
SD & & 36.26 \\
CoV $(\%)$ & & 9.62 \\
\hline
\end{tabular}


Table 5

Current Codes shear formulas.

\begin{tabular}{|c|c|c|c|c|}
\hline Code & \multicolumn{2}{|l|}{ Theoretical Shear (V) } & \multicolumn{2}{|c|}{ Parameters } \\
\hline & $\begin{array}{l}\text { Concrete contribution } \mathrm{V}_{\mathrm{cu}} \\
\qquad \text { Fibers contribution } \mathrm{V}_{\mathrm{fu}}\end{array}$ & & $\begin{array}{l}\text { Without } \\
\text { TR }\end{array}$ & $\begin{array}{l}\text { With } \\
\text { TR }\end{array}$ \\
\hline EHE-08 [40] & $\begin{array}{r}\mathrm{V}_{\mathrm{cu}}=\left[\left(\mathrm{C}_{1} / \gamma_{\mathrm{c}}\right) \cdot \xi \cdot\left(100 \cdot \rho_{\mathrm{l}} \cdot \mathrm{C}_{2}\right)^{1 / 3}+0.15 \cdot \sigma_{\mathrm{ck}}\right] \cdot \beta \cdot \mathrm{b}_{\mathrm{o}} \cdot \mathrm{d} \\
\mathrm{V}_{\mathrm{fu}}=\mathrm{k}_{\mathrm{f}} \cdot 0.7 \cdot \xi \cdot 0.5 \cdot 0.33 \cdot\left(\mathrm{f}_{\mathrm{R} 3 \mathrm{k}} / \gamma_{\mathrm{c}}\right) \cdot \mathrm{b}_{\mathrm{o}} \cdot \mathrm{d}\end{array}$ & $\mathrm{C}_{2}=\mathrm{f}_{\mathrm{cv}}$ & $\begin{array}{c}C_{1}=0.18 \\
\beta=1\end{array}$ & $\begin{aligned} C_{1} & =0.15 \\
\beta & =(*)\end{aligned}$ \\
\hline $\begin{array}{l}\text { EC-2 [37] + } \\
\text { RILEM [36] }\end{array}$ & $\begin{array}{r}\mathrm{V}_{\mathrm{cu}}=\left[\left(\mathrm{C}_{1} / \gamma_{\mathrm{c}}\right) \cdot \xi \cdot\left(100 \cdot \rho_{\mathrm{l}} \cdot \mathrm{C}_{2}\right)^{1 / 3}+0.15 \cdot \sigma_{\mathrm{ck}}\right] \cdot \beta \cdot \mathrm{b}_{\mathrm{o}} \cdot \mathrm{d} \\
\mathrm{V}_{\mathrm{fu}}=\mathrm{k}_{\mathrm{f}} \cdot 0.7 \cdot \xi \cdot 0.18 \cdot\left(\mathrm{f}_{\mathrm{R} 4 \mathrm{k}} / \gamma_{\mathrm{c}}\right) \cdot \mathrm{b}_{\mathrm{o}} \cdot \mathrm{d}\end{array}$ & $\mathrm{C}_{2}=\mathrm{f}_{\mathrm{ck}}$ & $\begin{array}{c}C_{1}=0.18 \\
\beta=1\end{array}$ & $\begin{aligned} \beta & =0 \\
\mathrm{~V}_{\mathrm{cu}} & =0\end{aligned}$ \\
\hline $\begin{array}{l}\text { MC2010 [2, 3] } \\
\text { Without fibers: }\end{array}$ & $\mathrm{V}_{\mathrm{cu}}=\mathrm{k}_{\mathrm{v}} \cdot\left(\sqrt{ } \mathrm{f}_{\mathrm{ck}} / \gamma_{\mathrm{c}}\right) \cdot \mathrm{z} \cdot \mathrm{b}_{\mathrm{o}} \quad$ (Level III Approximation $)$ & ----------- & & \\
\hline $\begin{array}{l}\text { MC2010 [2, 3] } \\
\text { With fibers: }\end{array}$ & $\begin{array}{c}\mathrm{V}_{\mathrm{cu}}+\mathrm{V}_{\mathrm{fu}}=\left[\left(\mathrm{C}_{1} / \gamma_{\mathrm{c}}\right) \cdot \xi \cdot\left(100 \cdot \rho_{\mathrm{l}} \cdot \mathrm{C}_{2}\right)^{1 / 3}+0.15 \cdot \sigma_{\mathrm{ck}}\right] \cdot \beta \\
\mathrm{C}_{2}=\left(1+7.5 \cdot\left(\mathrm{f}_{\mathrm{Ftuk}} / \mathrm{f}_{\mathrm{ctk}}\right)\right) \cdot \mathrm{f}_{\mathrm{ck}}\end{array}$ & $\cdot b_{0} \cdot d$ & $\mathrm{C}_{1}=$ & \\
\hline
\end{tabular}

$T R=$ Traditional transverse reinforcement;

(*) $\beta$ depends on $\theta$ according to the formula in Appendix B; if $\theta=\theta_{e} \rightarrow \beta=1$. 
Table 6

Shear strength $(\mathrm{kN})$ calculated from the current Design Codes without safety factors.

\begin{tabular}{c|cccc}
\hline Specimen ID & $\boldsymbol{V}_{\text {test }}$ & $\boldsymbol{V}_{\boldsymbol{E H E O S}}$ & $\boldsymbol{V}_{\boldsymbol{E C 2}+\text { RILEM }}$ & $\boldsymbol{V}_{\boldsymbol{M C 2 0 1 0}}$ \\
\hline HF600TR/1 & 571.61 & 491.21 & 337.03 & 474.40 \\
HF600TR/2 & 592.70 & 491.21 & 337.03 & 474.40 \\
H600TR/3 & 491.34 & 384.99 & 224.82 & 404.34 \\
\hline HF600/4 & 392.40 & 281.62 & 290.97 & 249.58 \\
HF600/5 & 347.20 & 281.62 & 290.97 & 249.58 \\
HF400h/6 & 420.00 & 298.81 & 308.86 & 261.58 \\
HF400/7 & 390.00 & 292.91 & 302.40 & 259.42 \\
HF400/8 & 428.30 & 292.91 & 302.40 & 259.42 \\
HF260/9 & 325.60 & 292.19 & 300.72 & 269.24 \\
\hline
\end{tabular}


Table 7

Shear contributions (\%) due to stirrups, concrete and fibers according to the current Design Codes

\begin{tabular}{|c|c|c|c|c|c|c|c|c|c|}
\hline \multirow{2}{*}{$\begin{array}{c}\text { Specimen } \\
\text { ID }\end{array}$} & \multicolumn{3}{|c|}{ EHEO8 } & \multicolumn{3}{c|}{ EC2+RILEM } & \multicolumn{3}{c|}{ MC2010 } \\
\cline { 2 - 10 } & Stirrups & Concrete & Fibers & Stirrups & Concrete & Fibers & Stirrups & Concrete & Fibers \\
\hline HF600TR/1 & 46 & 33 & 21 & 67 & 0 & 33 & 47 & 53 \\
HF600TR/2 & 46 & 33 & 21 & 67 & 0 & 33 & 47 & 53 \\
\hline H600TR/3 & 58 & 42 & 0 & 100 & 0 & 0 & 56 & 44 & 0 \\
\hline HF600/4 & 0 & 63 & 37 & 0 & 61 & 39 & 0 & 100 \\
HF600/5 & 0 & 63 & 37 & 0 & 61 & 39 & 0 & 100 \\
HF400h/6 & 0 & 63 & 37 & 0 & 61 & 39 & 0 & 100 \\
HF400/7 & 0 & 64 & 36 & 0 & 62 & 38 & 0 & 100 \\
HF400/8 & 0 & 64 & 36 & 0 & 62 & 38 & 0 & 100 \\
HF260/9 & 0 & 68 & 32 & 0 & 66 & 34 & 0 & 100 \\
\hline
\end{tabular}




\section{Appendix A. Notation}

$A_{p} \quad$ cross-sectional area of prestressed reinforcement

$A_{s} \quad$ cross-sectional area of longitudinal tension reinforcement

$A_{\alpha} \quad$ traditional shear reinforcement area

$b_{f} \quad$ flange width

$b_{o} \quad$ web width

$d \quad$ effective depth

$f_{c t k} \quad$ characteristic tensile strength value for the concrete matrix

$f_{\text {Ftuk }}$ characteristic ultimate residual tensile strength value for fiber-reinforced concrete

$f_{p 0} \quad$ stress in strands when the strain in the surrounding concrete is zero

$f_{R 3 k}$ residual flexural tensile strength corresponding to CMOD=2.5mm (according to EN 14645 )

$f_{R 4 k}$ residual flexural tensile strength corresponding to $\mathrm{CMOD}=3.5 \mathrm{~mm}$ (according to $\mathrm{EN} 14645$ )

$f_{y \alpha, k} \quad$ yielding strength of shear reinforcement steel

$k_{f} \quad$ factor for taking into account the contribution of the flanges in T-sections (EHE08 and RILEM)

$V_{c u} \quad$ design shear resistance attributed to concrete

$V_{f u} \quad$ design shear resistance attributed to fibers

$V_{s u} \quad$ design shear resistance provided by shear reinforcement

$V_{u 2}$ design shear resistance

$z \quad$ internal lever arm corresponding to the maximum bending moment. In the shear analysis, an approximate value $\mathrm{z}=0.9 \cdot \mathrm{d}$ can be normally used.

$\alpha \quad$ inclination of stirrups in relation to the beam axis

$\gamma_{c} \quad$ partial safety factor for concrete material properties

$\gamma_{s} \quad$ partial safety factor for the material properties of reinforcement and prestressing steel

$\varepsilon_{x} \quad$ longitudinal strain at the mid-depth of the member

$\theta \quad$ inclination of the compression stresses

$\theta_{e} \quad$ reference angle of cracks inclination

$\xi \quad$ factor that takes into account the size effect

$\rho_{l} \quad$ reinforcement ratio for longitudinal reinforcement

$\rho_{w} \quad$ percentage of shear reinforcement

$\sigma_{c k} \quad$ average stress acting on the concrete cross-section for an axial force due to prestressing actions 
Appendix B. Parameters determination and its limitations

$\xi=1+\sqrt{ }(200 / \mathrm{d}) \leq 2.0$

Common limitations for all Codes:

$\rho_{\mathrm{l}}=\left(\mathrm{A}_{\mathrm{s}}+\mathrm{A}_{\mathrm{p}}\right) /\left(\mathrm{b}_{\mathrm{o}} \cdot \mathrm{d}\right) \leq 0.02$

Particular limitations of each Code:

$\sigma_{\mathrm{ck}}=\left[\left(\mathrm{N}_{\mathrm{k}}+\mathrm{P}_{\mathrm{k}}\right) /\left(\mathrm{b}_{\mathrm{o}} \cdot \mathrm{d}\right)\right]<0.30 \cdot \mathrm{f}_{\mathrm{ck}} \leq 12 \mathrm{Mpa}($ EHE-08)

$\sigma_{\mathrm{ck}}=\left[\left(\mathrm{N}_{\mathrm{k}}+\mathrm{P}_{\mathrm{k}}\right) /\left(\mathrm{b}_{\mathrm{o}} \cdot \mathrm{d}\right)\right]<0.2 \cdot \mathrm{f}_{\mathrm{ck}}(\mathrm{EC} 2$ and MC2010 for FRC)

$\mathrm{k}_{\mathrm{f}}=1+\mathrm{n} \cdot\left(\mathrm{h}_{\mathrm{f}} / \mathrm{b}_{\mathrm{o}}\right) \cdot\left(\mathrm{h}_{\mathrm{f}} / \mathrm{d}\right) \leq 1.5($ EHE08 and RILEM)

$\mathrm{n}=\left[\left(\mathrm{b}_{\mathrm{f}}-\mathrm{b}_{\mathrm{o}}\right) / \mathrm{h}_{\mathrm{f}}\right] \leq 3$ and $\mathrm{n} \leq\left(3 \cdot \mathrm{b}_{\mathrm{o}} / \mathrm{h}_{\mathrm{f}}\right) \quad($ EHE08 and RILEM $)$

$\mathrm{V}_{\mathrm{cu}, \min }=\left[\left(0.075 / \gamma_{\mathrm{c}}\right) \cdot \xi^{3 / 2} \cdot \mathrm{fcv}^{1 / 2}+0.15 \cdot \sigma_{\mathrm{ck}}\right] \cdot \mathrm{b}_{\mathrm{o}} \cdot \mathrm{d}($ EHE-08)

$\mathrm{V}_{\mathrm{cu}, \min }=\left[0.035 \cdot \xi^{3 / 2} \cdot \mathrm{fcv}^{1 / 2}+0.15 \cdot \sigma_{\mathrm{ck}}\right] \cdot \mathrm{b}_{\mathrm{o}} \cdot \mathrm{d}(\mathrm{EC} 2$ and MC2010 for FRC)

$0.5 \leq \operatorname{cotg} \theta \leq 2.0 \rightarrow 26.57^{\circ} \leq \theta \leq 63.43^{\circ}($ EHE-08)

$1 \leq \operatorname{cotg} \theta \leq 2.5 \rightarrow 22^{\circ} \leq \theta \leq 45^{\circ}(\mathrm{EC} 2)$

$\beta$ determination (EHE-08):

$\beta=(2 \cdot \operatorname{cotg} \theta-1) /\left(2 \cdot \operatorname{cotg} \theta_{\mathrm{e}}-1\right)$; if $0.5 \leq \operatorname{cotg} \theta<\operatorname{cotg} \theta_{\mathrm{e}}$

$\theta=29^{\circ}+7000 \cdot \varepsilon_{\mathrm{x}}$

Parameters influencing $V_{c u}(M C 2010)$ :

$\varepsilon_{\mathrm{x}}=\left[\mathrm{M}_{\mathrm{Ed}} / \mathrm{z}+\mathrm{V}_{\mathrm{Ed}}+0.5 \cdot \mathrm{N}_{\mathrm{Ed}}-\mathrm{A}_{\mathrm{p}} \cdot \mathrm{f}_{\mathrm{p} 0}\right] /\left[2 \cdot\left(\mathrm{E}_{\mathrm{s}} \cdot \mathrm{A}_{\mathrm{s}}+\mathrm{E}_{\mathrm{p}} \cdot \mathrm{A}_{\mathrm{p}}\right)\right]$

$\mathrm{k}_{\mathrm{v}}=0.4 \cdot 1300 /\left[\left(1+1500 \cdot \varepsilon_{\mathrm{x}}\right) \cdot\left(1000+0.7 \cdot \mathrm{k}_{\mathrm{dg}} \cdot \mathrm{z}\right)\right]$ if $\rho_{\mathrm{w}}=0$

(B.15)

$\mathrm{k}_{\mathrm{v}}=0.4 /\left(1+1500 \cdot \varepsilon_{\mathrm{x}}\right) \quad$ if $\rho_{\mathrm{w}} \geq 0.08 \cdot \sqrt{ } \mathrm{f}_{\mathrm{ck}} / \mathrm{f}_{\mathrm{yk}}$ 


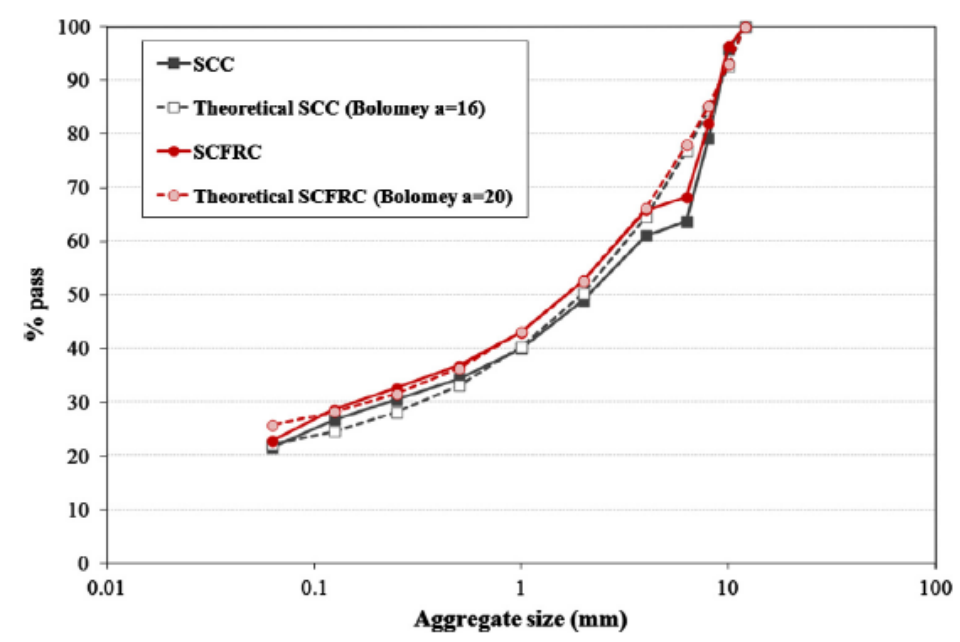

Fig. 1. Theoretical versus actual particle-size distribution curves for selecting the mix design.

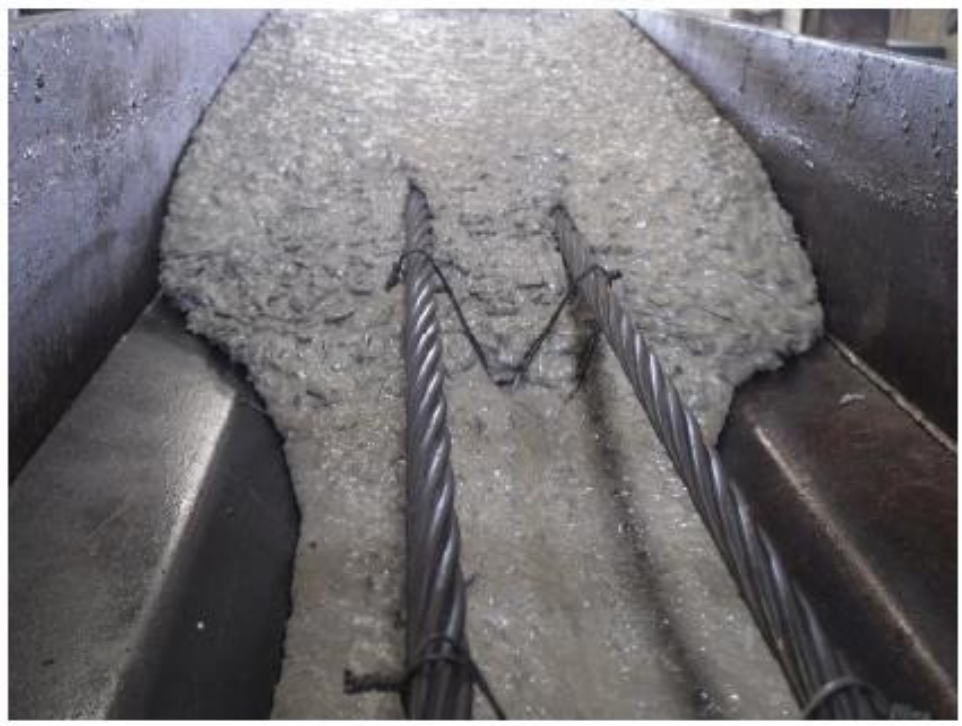

Fig. 2. Concrete pouring into the formwork.

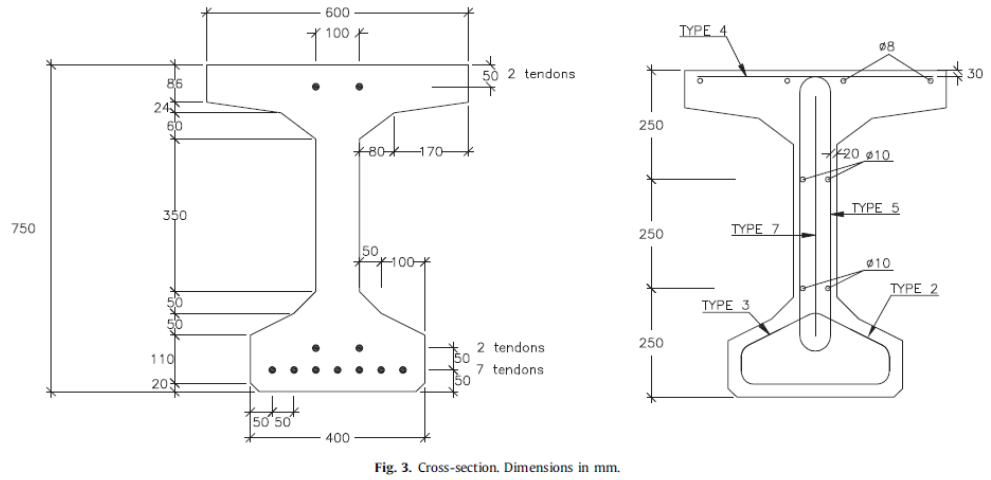




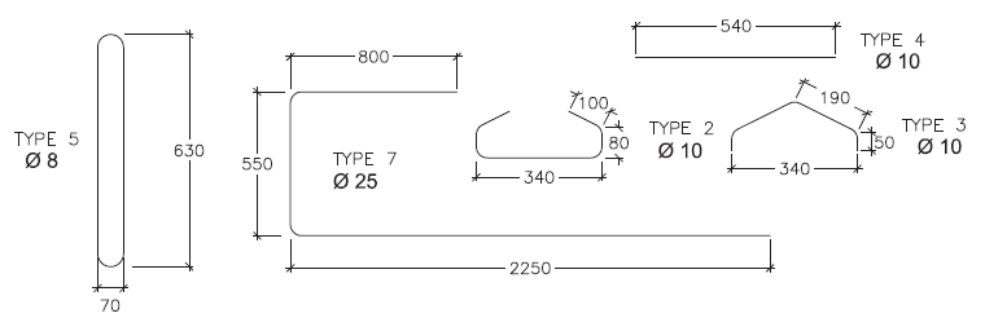

Fig. 4. Additional reinforcement typologies. Dimensions in mm.

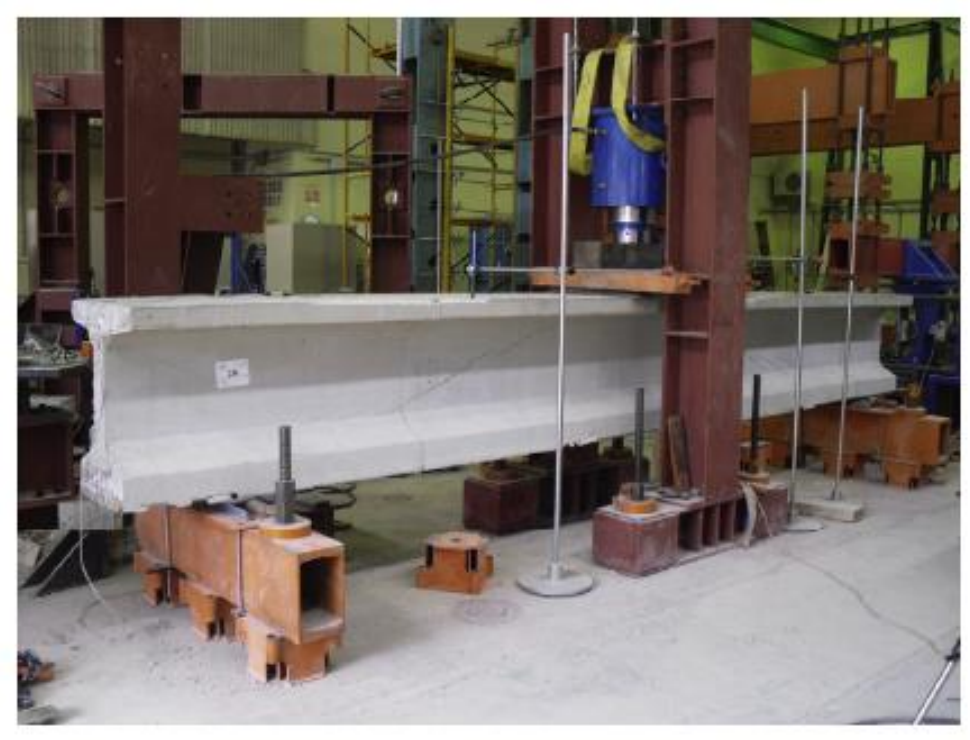

Fig. 5. Beam during shear test.

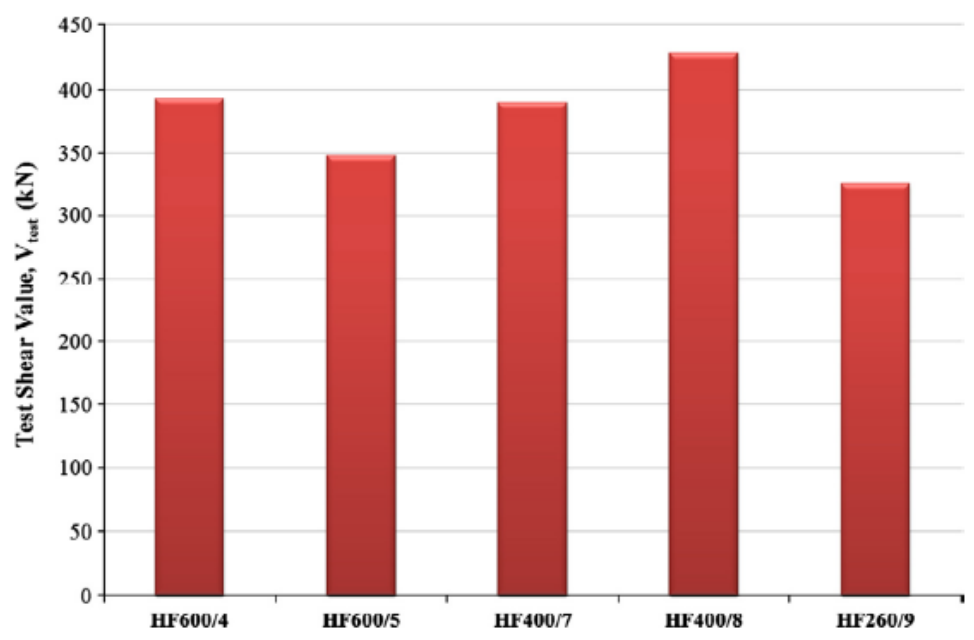

Fig. 6. $V_{\text {test }}(\mathrm{kN})$ comparison of fiber-reinforced beams with variable top flange width. 


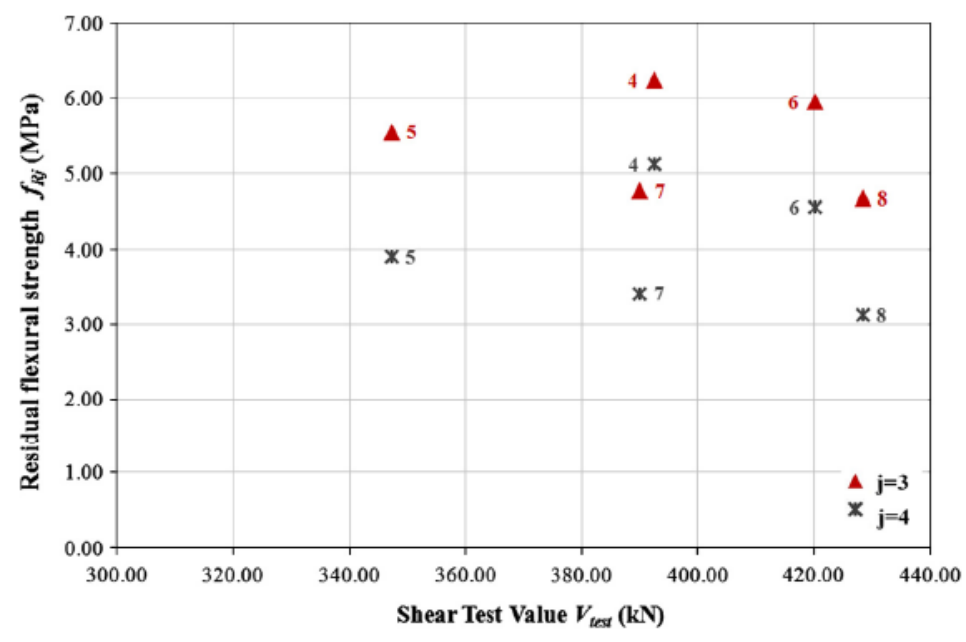

Fig. 7. $V_{\text {test }}-f_{R j}$ response of individual beams (beam number is next to each point).

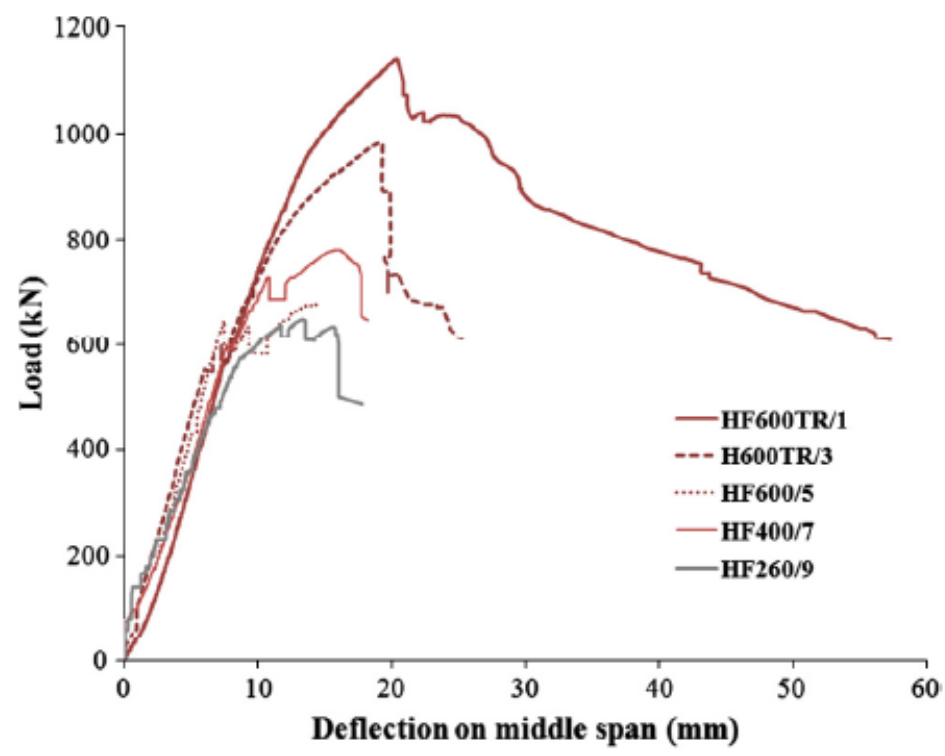

Fig. 8. Load-deflection responses on middle span.

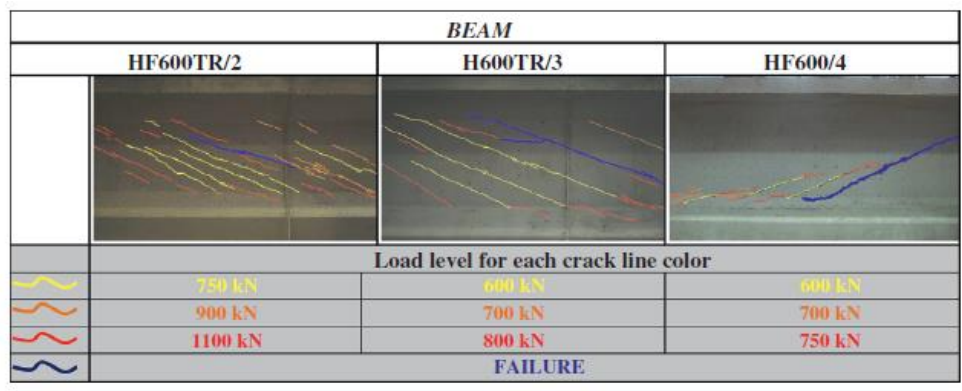

Fig 9. Cracking patterns. Crack appearance and the corresponding load. 


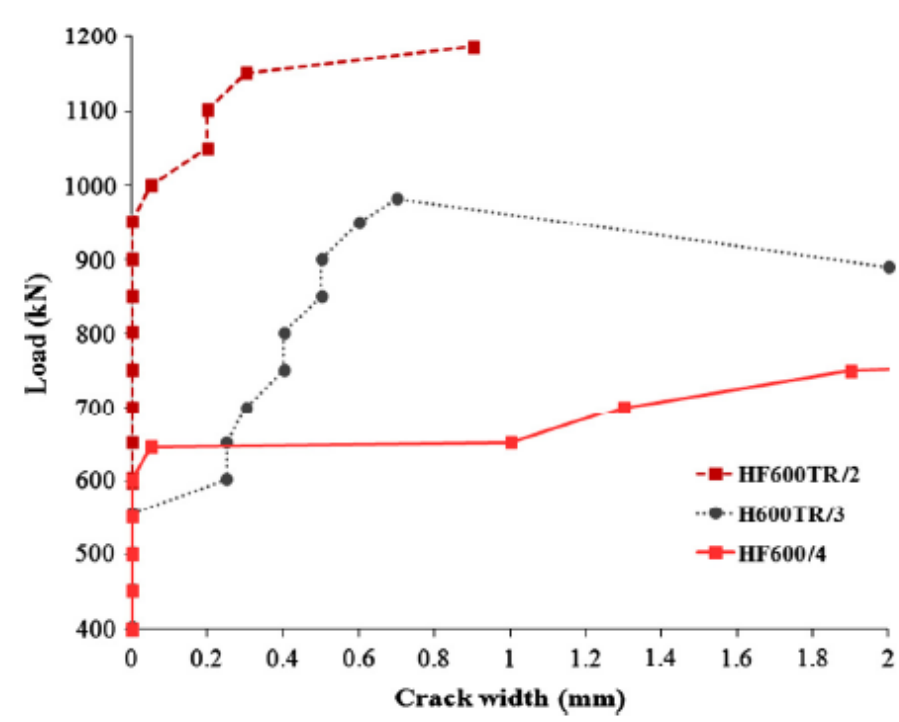

Fig. 10. Crack widths $(\mathrm{mm})$ in beams for different shear reinforcement combinations.

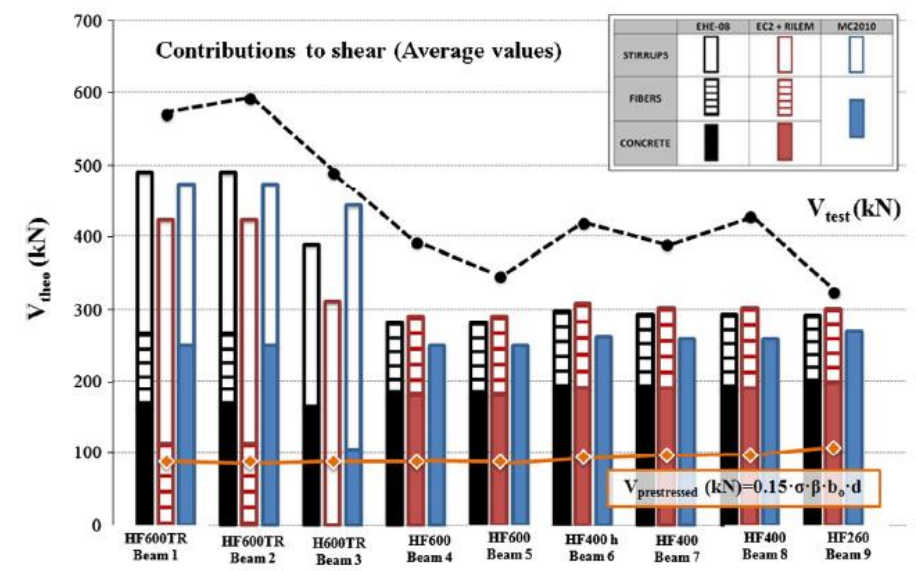

Fig. 11a. Contributions of concrete, stirrups and fibers to the ultimate theoretical shear strength capacity (average values).

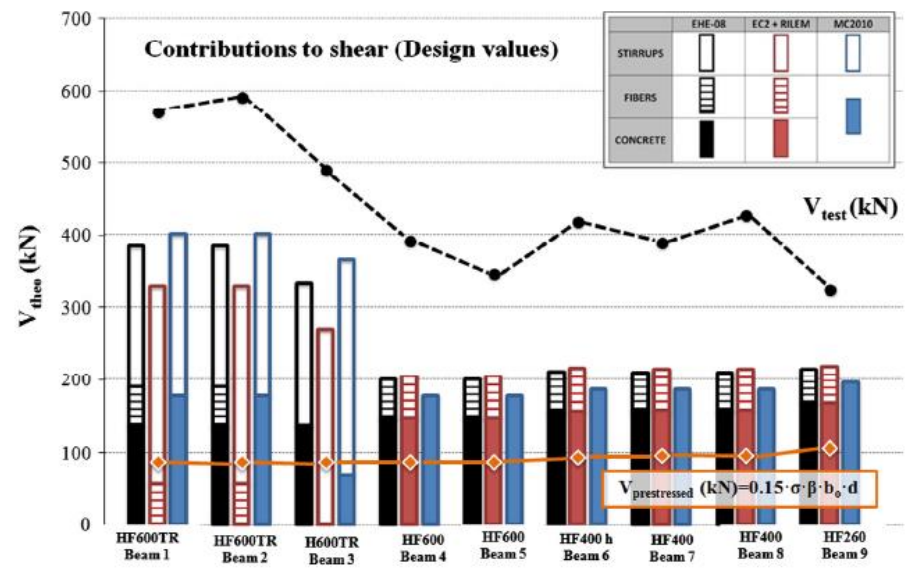

Fig. 11b. Contributions of concrete, stirrups and fibers to the ultimate theoretical shear strength capacity (design values). 


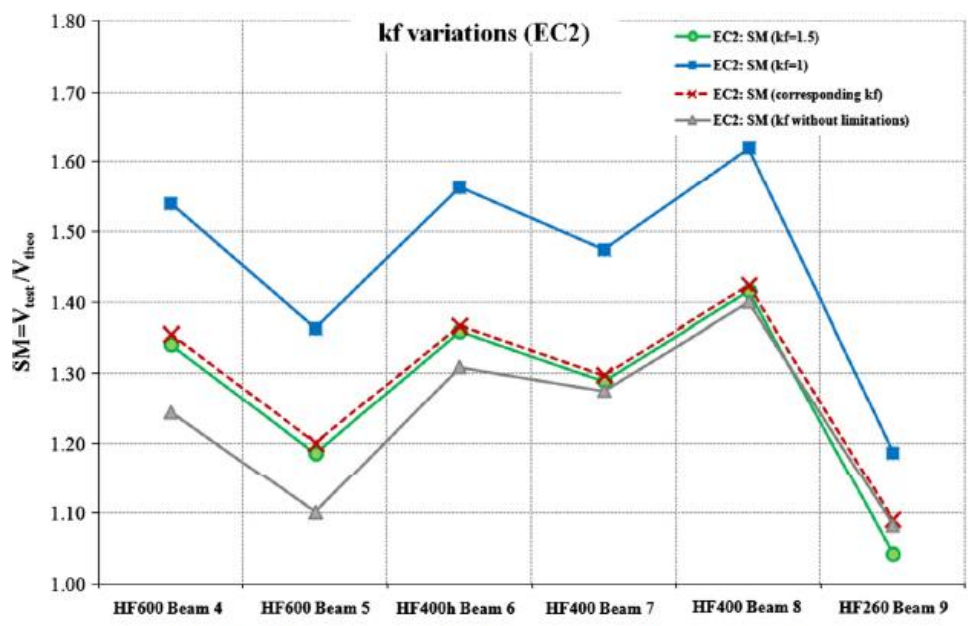

Fig. 12. SM variations when different flange factor values are applied.

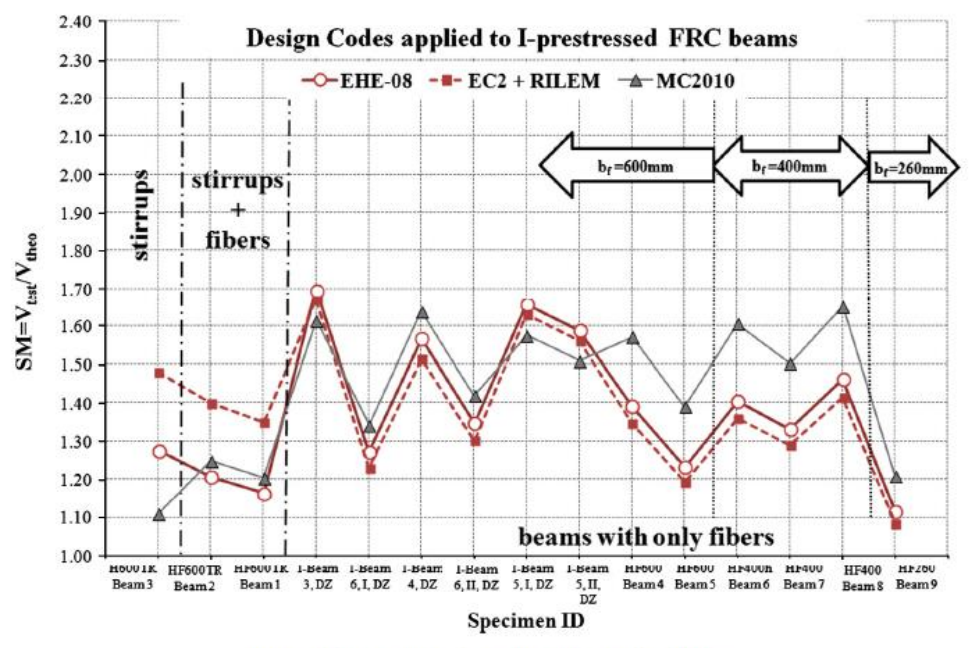

Fig. 13. Safety Margin $(\mathrm{SM})=V_{\text {test }} / V_{\text {theo }}$ without safety factors. 